\title{
STEREOPSYCHOLOGY AND STUDIES ON K'AN, FOUNDED BY RYO KURODA
}

\author{
NOBORU OHTSUKA
}

Konan University, Kobe

Thirty years ago Ryo Kuroda wrote a paper with regard to ' $k$ 'an' experience, and he had been taking a great interest in the subject to his grave since. He elaborated on his ideas in two books and several papers including three papers in English. His main thesis was that our experience consists of comprehension and consciousness. 'Comprehension' was used by him as an English word for ' $k$ 'an(勘)' which means in some respects knack or hunch, but he preferred comprehension to others on account of the broader meaning of the term. Comprehension, he asserts, is something another than an act of consciousness. I will give here a brief sketch of his comprehension theory with his own words as closely as possible, because his thought, as an example of Oriental psychology, should be given more attention by Western psychologist respecting to such subjects as learning, skillfulness, religious experience and the fundamental structure of mental activity itself.

\section{Comprehension Appeared in Volitional Actions}

As regards the experience of comprehension we can easily find many instances of it in special experiences such as Japanese fencing, Kabuki-play, No-play and Zen-Buddhism: those considered by Kuroda mainly in his first book "Studies on K'an." According to his view, these mental activities not only exist in specialist, past masters or experts, but are more general in its nature and we are able to find these activities in experiences of everyday life. Therefore it is to be expected to exist several kinds of comprehension: cognitive, affective, volitional, pertaining to memory, imagination, judgment, action etc. But comprehension is most vividly experienced where it appears particularly in connection with the mental process of cognition and judgment as well as of voluntary phenomenon and action.

He takes up a habit as an example of comprehension. After a voluntary action becomes reflex-like, we are no longer conscious of any particular phase of the moments; only when the progress of movement be obstructed by some circumstances, we come to ourselves with a start, i.e. our consciousness renews to act. But we cannot identify these retrogression of consciousness with those produced by the absolute unconscious. The movement itself may be taken for nearly automatic, but it can never be permitted that there exists nothing in our mind, that is, the movement goes on with an absolute automatism. However skilled an action may become, our consciousness will receive all the time a certain form of report as long as it proceeds. This can easily be realized if we compare the experience with those automatic physiological activities such as circulation or digestion. The thesis that practice mechanizes volitional actions by means of repetition is right so long as it is understood in a figurative sense, yet it is a mistake to think that human activities, at least those having volitional origin, are performed just as automatically as real machinery. Voluntary actions, even 
after they have been transformed into nearly automatic mechanism, are connected with the ideas to be attained in the end through an invisible thread so to speak and give us such an inpression as if they were drawn in through the agency of the thread towards its goal. Accordingly the end idea has dynamic characteristics to the extent that they regulate and control every particular phase of activities by means of an invisible thread. This dynamic side is the essential criterion of all volitional actions in general and their derivatives.

\section{Comprehension in COMParison With OTher Theories}

With regard to these points Ach had shown that besides the phenomenal criteria of volitional activities there is a substantial criterion, the so-called dynamic moment, which characterizes determining tendencies peculiar to end-ideas or ideas of problem. Except at the moment when the activities start on, the determining tendencies operate during the while in which they are proceeding. Though it is not clear that Ach means by the term, determining tendencies, whether certain physiological processes underlying volitional experiences or not, Kuroda assumes that he would means certain physiological processes when we consider that he speaks of Bewusstheit under which is implied a non-intuitive knowing. While otherhand Ach emphasizes that the actual moment, one of phenomenal criteria, exhibits above all dynamic characteristics of volition. It is therefore a question to regard these determining tendencies in particular as the proper dynamic moment. The mental attitude by which successive phases of an action are regulated by an invisible thread, however, may be no more than the determining tendencies. These tendencies may be looked upon as a case of compreliension. In this sense of comprehension, being different from the case in which voluntary actions operate, it is only. Ach's objective moment which consists of the end-idea and relating presentative elements that stands rather on the foreground in our experience, while the other moments do not come on the verge of it. The objective moment itself may sometimes withdraw into the background of consciousness, yet it is those determining tendencies that act forcibly as before. It can not be denied that they have too close a relationship with our direct experience to be regarded as purely physiological processes, but the fact that they have intimate relation with our experiences does not necessarily imply that they are experienced in our consciousness; they have, however, such proper quality as we positively assert that they have no phenomenal relation with consciousness. The real state of mind is such that we real1y know of the existence of thread, but are unable to witness actually with our own eyes. Because the thread is invisible, it has been looked upon by many as the unconscious. Thus there is no other way than to assume either the existence of two or more levels in consciousness or to admit only a single level which is affected in some form by physiological processes.

There is another mental state which comes to exist during the process of habit formation, the process of learning, and its characteristics are nearly similar to the above-mentioned. We rnust also expect the presence of the same mental states in the animal. Such are the processes. as neural tension, subexcitation or physiological friction, which Swift introduced in his exflanation of animal learning. And those were found also in human learning as far as the essential points are concerned. According to Kuroda the state of mind, which called Swift flysiological friction, is not pure physiological processes, but it is nothing but varieties of 
comprehension distinguishable from consciousness together with the so-called consciousness of fringe originated in James' psychology. He maintained that we must acknowledge with James that there exists what can not be grasped at all, and yet acts vigorously, and this has been often ignored, or though noc ignored, expelld from its due place as belonging to a realm above description and buried under an epitaph of the unconscious or the subconscious. Thus he intended to revive it in the form of comprehension and to emphasize with James that though it does not take an active part on the foreground of our concrete actual experience, it occupies none the less vital and extensive factors which constitutes it.

Further he insisted that Ach's Bewusstheit, Marbe's Bewusstseinslage and Bühler's Gedanke, be their significance what it may, are founded after all on the same or at least similar state of our experience and all can be taken for a form of comprehension which appears in connection with cognition and judgment. Ach emphasizes those characteristics which are given non-intuitively, while Marbe's Bewusstscinslage is distinguished by the fact that it is a unique experience which is not reducible into any conscious elements. Kuroda doesn't subscribe to Ach's view because he suspects that Ach in reality identifies Bewusstheit or its nonintuitiveness with unconscious. On the other hand, although he is in favour of Marbe's theory so long as many Bewusstseinslagen pertain to situation in addition to cognition and knowing, but he critisizes the theory as one that it is a mere attempt to give an unsubstantial term to a fact to be explained. It is his opinion that comprehension participating in cognition or judgment is not, as far as it is a form of comprehension in general, essentially different from that in action and will and never of a nature beyond all description, only it is difficult to analyse it in forms of traditional rules so confidently as in the case manifested in the form of consciousness. Hence it follows that the problem concerned has been either discarded on account of unintelligibility of its real states of affairs or, though by chance submitted to analysis, only negatively determined by dint of difficulty to approach. This neglected problem or these uncontrollable facts make rather a central or more often the first thing to be attacked in Oriental psychology, all her efforts seem to have been concentrated upon them.

\section{Some Characteristics of Comprehension}

Several forms of our direct experience, known for instance as the sixth sense, the unconscious, automatically mechanized practice, a divine skill, inspiration, spiritual awakening, a state of Dhyana, telepathy, a knack, etc. presuppose a common unique factor which differentiates them from other daily conscious experiences. They, Kuroda claimes, have each such a peculiar characteristic that they are pregnantly given in spite of involving a feeling of perfect master of respective details of activity. Though we can experience it along almost every line of our practical life if proper conditions be prepared at all, it makes its appearance most strikingly in the case where a special skill is necessitated to neet the situation.

To bring these facts clearly he gives an example of handling microtome in microscopic technique. After we have mastered the use of a microtome, we can make a prediction as to the final results of a preparation simply from our feeling experienced at the instant of cutting, notwithstanding the fact that we do not know how and whence it comes. This state of mind is never such that can be termed dim and obscure of chaotic consciousness or else the 
unconsious as it often urged by some authors. Though nothing is known about parts, the whole seems to be transparent and clear-cut as it were; it is not enough to say simply of its positive vacancy, as was suggested by James with reference to his consciousness of fringe. Speaking in brevity it is an experience having a depth, a state of ultimate reality or something to that effect.

Following illustration might serve to show how can we have such experience of depth. As long as we are fumbling in the dark in order to attain some cue to meet the urgent requirement, we can find nothing but a surface which has no depth and merely reflects light that reaches there from without, but according as we are aquainted with the knack of performance there will result plenty in reserve with which we can more calmly get at the bottom of it and at the same time the surface which has been deemed as reflecting all coming light proves in reality to have a transparent structure through which a background scattered with varied objects is able to be discerned. At the ealier stage conscious activities play a leading role and at the time, knack happened, comprehension appears.

If we assume that our total field of experience consists of a world of conscious face and that of depth surrounded by such face, the former will come into existence out of materials given from without, while into the latter can we penetrate only after a sort of volitional elaboration has been executed within. Such penetration into depth may be termed psychical stereoscopy, and the object of stereopsychology is to establish and describe its phenomenal aspects and proceed to analyse the conditions of its existence. Stereopsychology is not solid in the same sense as is the case in stereochemistry which has to do with the arrangement of molecules of an atom in space. Conscious molecules do not be arranged actually likewise in spatial constitution. The same is true with regard to face: we assume a world of experience comprehended by us only in case we stand on a certain specific point of view in accordance with the foundation analogous to the effect that actual space has a dimension of depth besides face.

Though a comprehensive experience is not always necessitate to be accompanied by consciousness, we usually aware, if both intersect each other, of only a clear or sometimes vague image coming upon the scene of consciousness, all our mental operation seems to proceed smoothly carrying that image at its center, yet at the same time there is some sort of clear serenity which, to speak figuratively, is objectified in the feeling as if we are thoroughly informed concerning its every particular although it be in reality a large outlook of the whole. Such a feature begins to shoot little by little as the formation of comprehension. proceeds and reaches to perfection when it is completed.

\section{AESTHETIC AND ReLIGIOUS EXPERIENCES}

Aesthetic experiences also are for the most part nothing but forms of comprehensive experience. In a picture as well as in a melody there is beauty where particular contents given temporally one after the other are unified within a world of comprehension tending towards a certain direction. This is the case also with respect to pleasantness which we feel while we are doing some act. As long as a voluntary action is being performed, we are neither incessantly conscious of its end before our mind nor is it motivated by resulting pleasure. These factors may act more or less vigorously at the first instance of commencing such 
activity, but after a beginning is once made they will retreat to the backgroud, giving way to comprehension which regulates every bit of activity that it may proceed smoothly along the beaten path opened by past experience. Feeling of pleasantness is nothing but a response of comprehension to a fact that respective bits of an activity are being brought to completion in serial order along a pre-established track.

Comprehension, or penetration into depth of experience, is thus in most cases an outflow from preceding hard toil and labor which enable us to find our way without any help from outside, and as for this sort of comprehension, the first step up to which is to devote oneself to whatever one makes up one's mind to master, and then in order to complete it, it is further necessary to rise above the present state of affairs; in other word, thorough immersion in an event is to be followed by transcendence over itself or paradoxically as it may sound by a disinterested concern. Tranquility or peace of mind will thus be realized.

\section{Polarization}

In an experimental investigation concerning to comprehension Kuroda ascertained that three observers in his experiment can perform several things at a time, that is, in the most difficult problem in the last section of the experiment they are able to perform even quadripolar activities, including discriminative throw of balls with the left hand, discriminative finger reaction of the right hand, mental arithmetic and retention of unrelated words. The experimental results were explained by him in the light of polarization theory, which was that assuming two realms, consciousness and comprehension, in our mind, each has its pole respectively, and that while consciousness has always a single pole, comprehension is possible to have several ones. Existence of a unitary pole in consciousness determines "one thing at a time"; if more things be made to operate by force, there will inevitably result in confusion. Thus by quadripolar activities is meant a state of coexistence of one pole of consciousness and three poles of comprehension.

A task given to an organism is an incentive to polarization, not the polarization itself. Whether a process of polarization takes place or not, depends upon the nature of a task which is consistent with the urge of an organism, which will give rise to actual polarization. For the learning process he also gives a explanation from his view point. In learning process we are always guided by a invisible thread to its goal as such above mentioned habit formation. This happens when we are taken to a specific situation, where we carry out the learning task at a fixed place and time along the routine. At the moment we step into the situation, we have a certain feeling or mood, drawing to us, which is an important factor to lead step by step the learning process to the final goal. Even in the animal learning we can find the same case. It is not unusual case to observe that after several trials animal, rat or monkey comes near taking a positive attitude to solve the task. This is polarization itself that results from the commencement of a learning. In this sense a completion of maze learning in albino rat is no less than a establishment of a pole in polarization, in other words, completion of a learning can be said to grasp the object of learning at 'na i tien 那一点' (vital point or essential point), that is, insight or penetration into the object. The enlightenment or study of Zen Buddhism also may be explained as something that has relation to polarization. 


\section{Na I Tien, Chin Chin and Chi}

$\mathrm{Na}$ i tien will be explained as follows: When we observe a thing, it may be possible to observe it from various view points. For instance, when I looked upon my penholder with which I am writing this paper, I can look at the penholder with a specific attitude of mind as instructed by an experimenter in the usual case of psychological experiment either to observe all over it from end to end and to report it with closed eyes, or to pay attention to size or shape of particular part of it which I hold it of. It may be acknowledged that thus the same thing may be grasped by us in different forms according as what we require. Observation without relation to the requirement of subject, no matter whether it is forced by any one or arises spontaneously, is meaningless. Things should be observed by man to meet his requirement. The penholder I am used to several years has a different characteristic, familiarity, compared with that observed in a laboratory. Although, attending to the details of it, I find any unusual points which have been never before aware of, this is often done at the experimental observation, yet I am able to write anything I want as if it were my own hand, and am familiar with it as before. In comparison with experimental observation, the penholder is the same as a physical substance, but is different in its psychological naturc. Now a center of the penholder appears and represents the whole penholder. It is impossible to denote physically where this center is, I dare say it localizes about at the point which I grip on. This center is felt not only when I write with it but also when it is put in a inkstand. The center is called 'na i tien'.

$\mathrm{Na}$ i tien means a vital point or essential point. Concept, in logical sense, seems to be alike it by appearance, but both are quite different in its nature. $\mathrm{Na}$ i tien is a more concretc than concept and the whole of object is concentrated in it and supported by it, namely, it is a functional center of the object. When we think that object is not mere objective existence which is separated from subject, but is something which has a organic relation to subject, we have a familiarity feeling. This is a symptom of the establishment of na i tien. $\mathrm{Na}$ i tien does not appear so long as we perceive something by means of our bodily eyes, and only repeat the action many times. A close observation in full detail, that may be brought to a increasing state of clearness of a concept, does not give assurance that na i tien takes place. Only when the object is brought into the life circle of the subject, the object can be grasped at the vital point na i tien. $\mathrm{Na}$ i tien is also established in a process of thinking, and as an idea or concept is grasped at na $\mathrm{i}$ tien, the thinking will smoothly proceed along its essential line. To grasp the object at na $\mathrm{i}$ tien is called 'chih chih 直 指' (directive grasping, insight or penetration), which originates from Zen Buddhism where is a habit of saying "Insight into human mind."

I must lastly refer to 'chi 機' (chance or opportunity). By chance we may succeed in doing something, but in other case, often we can not seize a good opportunity in spite of we exert all our efforts in favor of success, especially to make a better achievement after the completion of a learning. The chance is given from outside heteronomously in the former and in the latter it is seized autonomously by the subject. We must, however, acknowledge that both cases have a particular significance respectively without regard to the difference. Chi belongs to the objective world in nature and appears momently in the changeable processes. The subject itself, therefore, must prepare for seizing the chance. The preparation 
will be easily done when the establishment of a pole takes place in the situation, owing to the fact that a pole will open the way to pay attention to another activity. Thus polarization plays its role in these situations.

It seems to me that some authors, including psychologists and psychiatrists, feel an interest in Zen Buddhism recently. It may also be worth while for them to pay attention to Kuroda's psychology, who devoted his effort to the same subject in the main.

\section{REFERENCES}

1. Kuroda, R. Stereopsychology: its scope and method. Acta psychol. Keijo, 1931, 1, 69-82.

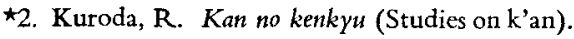
Tokyo: Iwanami, 1933.

3. Kuroda, R. Experimental studies on 'Kan.' I. Polarization of psychic activities. Acta psychol. Keijo, 1935, 2, 99-123.
*4. Kuroda, R. Zoku kan no kenkyu. (Studies on k'an. Continued). Tokyo: Iwanami, 1938.

5. Kuroda, R. Learning interpreted in the light of polarization. Acta psychol. Keijo, 1939, 3, 95-103.

* Written in Japanese

MS. received IV 10, 60.

Noboru Ohtsuka (大 塚 鐙 1905- ) Keijo Univ. 1937; Assistant, Keijo Univ.; Assistant Prof., Keijo Teachers Coll.; Prof., Osaka Coll. of Social Work; Prof., Konan Univ. 